\title{
Simple Design of Solar Based Watering System for Plants: Application in Multi-Story Buildings
}

\author{
Mrudula Hote, ${ }^{*}$, Ila Dvivedi \\ Delhi Public School, Roorkee, Uttarakhand (India)
}

\begin{abstract}
In this paper, the design of a solar-based watering system for plants in multi-story buildings is proposed. The main advantage of the design is that when the people are out of station or busy for particular days, the proposed solar-based system will water the plants for a particular time in a day. The proposed design is verified on a real-time hardware setup. The main advantage of the proposed design is that the mathematical approach is very simple and no need for any rocket science.
\end{abstract}

\section{Introduction}

East or west, going clean and green is always the best. Earth is called green due to the presence of plants. Plants are the backbone of all life forms on Earth and an essential resource for human well-being [1]."Go Green, India Green" this is what we are taught since our childhood this shows how much plants are important. From the air we breathe(by-product of photosynthesis) to the food we eat is directly or indirectly from plants. Plants help to maintain the water table thus regulate the water cycle. One-quarter of all prescribed medicines come directly from or are derivatives of the plants. Of course, aside from human usage, plants balance the ecosystem. Other species of fish and wildlife also depend for food and shelter on plants. Plants store carbon and have helped to reduce much pollution from excessive carbon dioxide produced from the burning of fossil fuels out of the atmosphere. Due to the increase in the number of Multistorey buildings, there is a decrease in the number of trees and hence increase in pollution levels in various cities [2]. Further due to the increasing population, the ratio between the humans (animals): plants is not balanced. For this, people can plant plants in their apartments. This is useful when the continuous water is available for the plants. But, today's family structure is different than the older times, i.e., due to the rise of nuclear family structure seen in today's lifestyle creates another problem of watering the plants as the family has to go out for many reasons like official work, Leisure, away from the native place. During that time, it is a challenging task to serve water to plants, as nobody is present inside the house. Therefore, we need a mechanism by which we can save the water in the multi-story building. In view of this, in this paper, a solar-based watering system for plants in a multi-story building is proposed. In this proposed approach, using solar energy [3, 4], power is supplied to the motor gun which activates the tap of the tank by which water is supplied to the plants for some specific time. The specific time is decided based on the position of the solar tracker, which can move horizontally or in the vertical direction. The main advantage of the proposed approach is that there is no need for any advanced communication technology such as Wi-Fi, mobile technology etc.

\section{Motivation}

We live 1000 s of kilometers away from our hometown and we go in summer and winter vacations over there but as we cannot carry our plants back with us as they stay in the balcony of our apartment of a multistory building. It is not possible to ask neighbours to water our plants as they have also their personal lives and sometimes they also go out for vacations and further asking your maid or any other person to water the plants is also point of security of home that made our mind for something that will give water to the plants when we are not at home. Moreover, the idea is to use solar energy because it is a renewable resource of energy, that will maintain the electricity bill and other advantages which we learned from various science books.

\section{Literature survey}

Various type of research work is carried on a solar-based watering system. The brief review of these works is as follows:

\subsection{Jia Uddin et al., (2012) [5]}

Authors of this paper, proposed a model of variable rate automatic microcontroller irrigation system. This is basically for farming purposes using sensors and mobile phones.

3.2 T A Binshad et al., (2016) [6]

*Corresponding author:mrudulahote@gmail.com 
Authors of this paper proposed PV based pumping system for agricultural irrigation. In this approach, power electronic controllers were designed. They have been developed for the water pumping system. In this, the boost converter is used along with an inverter followed by an induction motor pump set but this is also again for agricultural purposes and this approach is complex.

\subsection{K. Megalingam and Vamsy Gedela (2017) [7]}

Authors of this paper have discussed the concept of a solar-based smart irrigation system. In this design, they have used a microcontroller-based circuit board, sensors for agricultural purposes and it is used in such a manner i.e., particularly the switch is ON only when the moisture content in the soil is less.

\subsection{Abhishek Agrawal et al., (2018) [8]}

In this paper, they have a microcontroller-based irrigation system in which the sensor detects the moisture of soil and provides a signal to the motor to turn either ON or OFF the irrigating pump for proper utilization of water by the farmers.

The existing work is based on microcontrollers etc. but our system can be used for farming as well as for multi-story buildings. There is no need for sensors and microcontrollers. The methodology is very simple. This is explained below.

\section{Proposed set up}

The block diagram of the proposed set up is shown in fig. 1. In this figure, it is shown that the output of a solar panel is dc voltage. This voltage is possible only when the maximum solar energy from the Sunrays is directly in line with the solar panel. This solar panel is connected to the water tank with a motor gun that moves the water tap on the upper side through which water flows from the tank connected to a water pipe from where water reaches each plant by drip irrigation method.

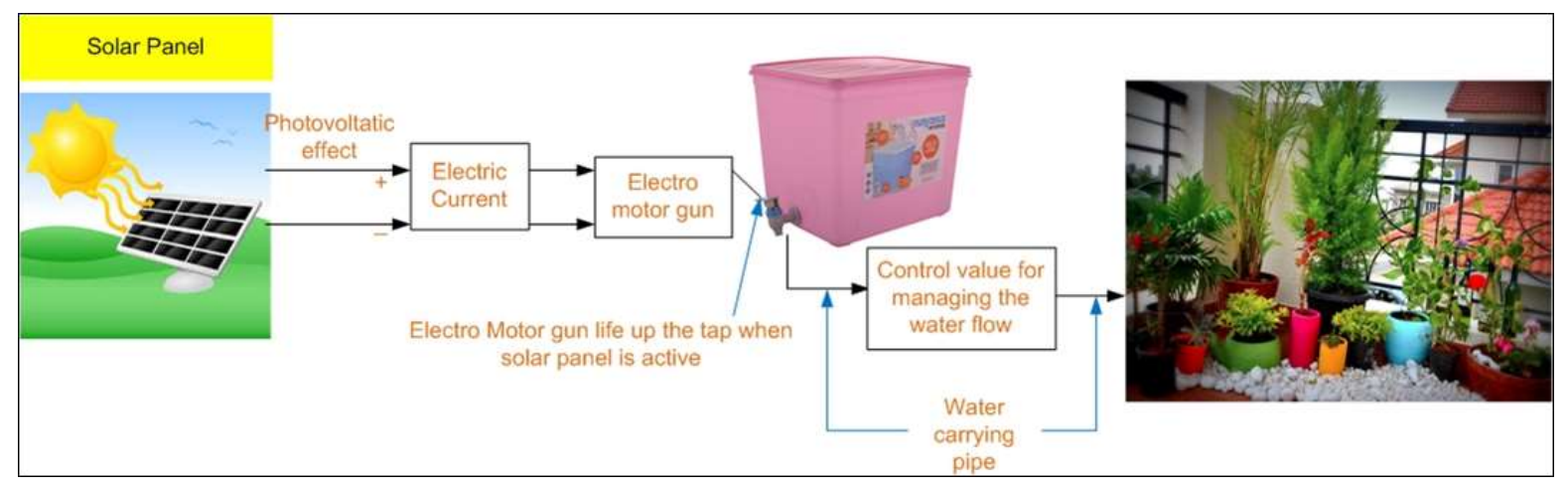

Fig.1. Proposed set up of solar water-based water system.

\section{Proposed real-time setup of solar- based watering system}

The proposed solar-based watering system is described below.

\subsection{Solar tracker System [3, 4]}

Solar panel voltage: $18 \mathrm{~V}$, Angle set for solar tracker is: 30 Degree, Horizontal and vertical motions are possible using solar tracker system. Fig. 2 shows the solar panel with the tracker system.

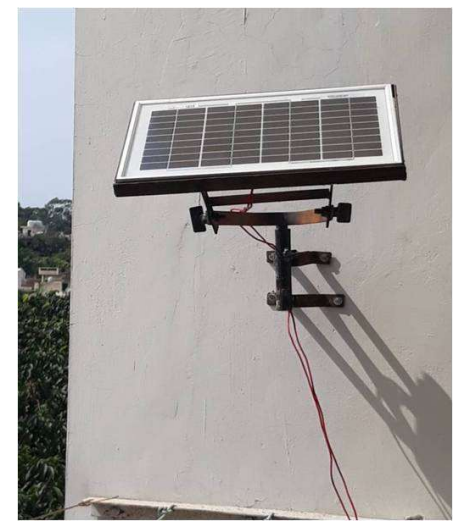

Fig.2. Solar tracker system 


\subsection{Tank system}

The various parts of the tank system are

- Water tank

- Motor gun (solenoid)

- Water tap

- Pipe

- Water flow controller

Fig.3. shows the tank system with a motor gun, water tap, pipe, and water flow controller.

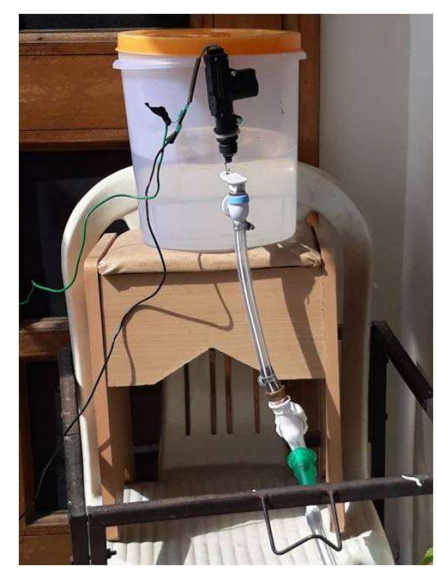

Fig.3. Tank system with motor gun

\subsection{Electric switch}

This switch is placed between a solar tracker system and the water tank system. This switch controls the opening of a water tap. When the switch is in off condition, even though there is solar energy, there will be no water flowing through the outlet. Fig.4 shows the electric switch, which activates the motor gun.

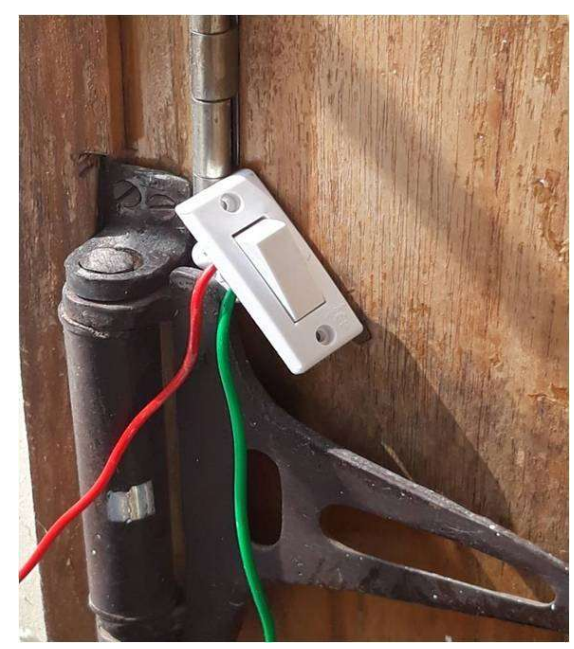

Fig.4. Electric switch which activates the motor gun.

\subsection{Plants in the balcony (four plants)}

There are four plants in the balcony. The pipe is placed near the plants as shown in fig.5. There are small holes made in the pipe by which water can drip easily.

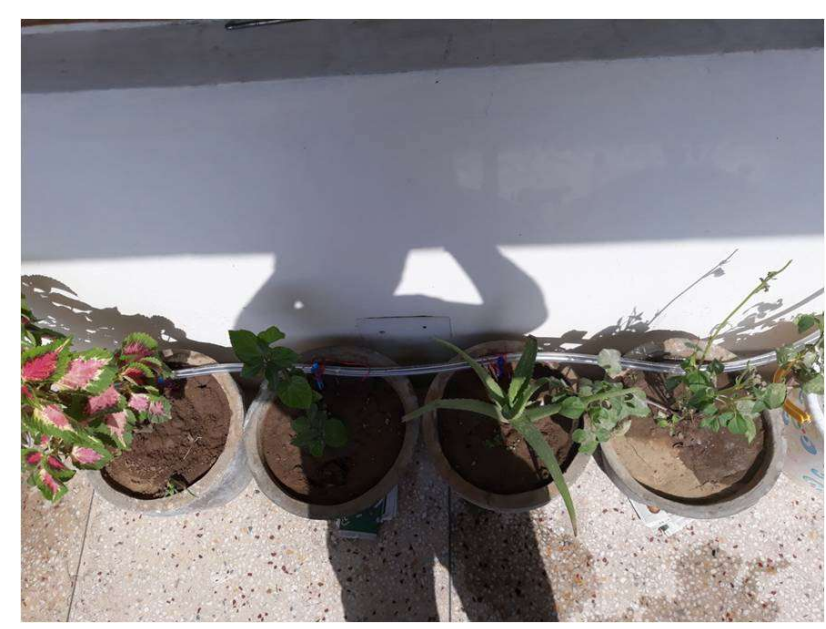

Fig.5. Four plants with pipe in the balcony.

The complete set up is shown in fig.6.

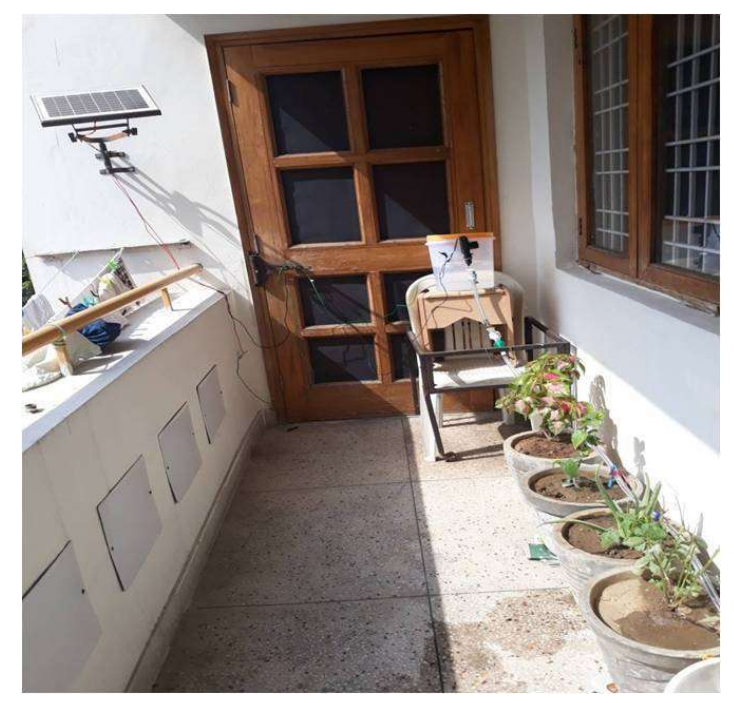

Fig.6. Complete set up of solar panel with water tank system.

\section{Proposed methodology}

\subsection{Proposed concept}

The proposed methodology is based on the concept of time during which solar energy is available which activates the solenoid. Once the solenoid is activated, the water tap will move in the upward direction and hence water will flow to the plants through the pipe. There are small holes that have been created in a manner that the 
water would be supplied to the plants through the holes of the pipe. This water will be available for the plants. The most important part is the water flow controller by which we can adjust the flow of water. The mathematical concept and based on this, application to watering the plants in the balcony are given in the following subsections.

\subsection{Mathematical formulation}

Consider, there are ' $n$ ' number of plants in the balcony. Assume that ' $y$ ' $\mathrm{ml}$ of water is sufficient for each plant. The quantity of water needed $(z, m l)$ is

$$
z=n y
$$

Suppose, we are out of station for ' $d$ ' days. Therefore, the total quantity of water requirement $(T)$ is given by

$$
T=n y d
$$

Assume that say for 1 hour, approximately ' $w$ ' $\mathrm{ml}$ of water is dispersed. Therefore, for $d$ days, we will require the following amount of water as given in eq. (3).

$$
K=d \times W
$$

The proposed design should be such that

$$
K=T
$$

\subsection{Application}

For experimental work, we have considered four plants in the balcony. It is assumed that $100-125 \mathrm{ml}$ of water is sufficient for each plant. Therefore, for four plants, $125 \mathrm{x}$ $4=500 \mathrm{ml}$ of water is required daily. Suppose, we are out of station for four days. Therefore, total water requirement is $500 \times 4=2000 \mathrm{ml}=$ Approx.: 2 litres. Through experimentation, it is observed that for the position of solar tracker as mentioned earlier, water flow is continuous nearly for 1 hour for a fixed position of a solar panel in our balcony at home. After that, gradual intensity of sunrays reduces on the solar panel and the tap will automatically come in the off position. By trial and error procedure (experimental analysis), we have adjusted the position of water flow controller (additional tap) in such a way that in 1 hour, approximately, 0.5 litre $(500 \mathrm{ml})$ of water will be dispersed. For 4 days: $4 \times 500=2000 \mathrm{ml}=2$ litre of water will be required in our case. If the number of plants is more, we can change the position of solar tracker and accordingly we can adjust the water flow controller tap and the size of the tank can be changed. This can be done using equations (2) and (3).

\subsection{Proposed result}

The actual values of voltage and current are measured using voltmeter and ammeter. From this, the total power produced by the solar panel is calculated. This is given as

The result of solar output:

Voltage (V): $2.315 \mathrm{~V}$

Current (I): $0.28 \mathrm{~A}$

Power $(\mathrm{P})=V \times I=3.315 \times 0.28=0.6482 \mathrm{~W}$

\section{Advantages and future scope of proposed work}

The focus of this project is simplicity. The proposed system is automatic. No need for any advanced technology such as mobile, wifi... etc. The proposed system is cost-effective. This system can also be used for day to day watering of the plants. No rise in the electricity bill. The complete system is safe and no environmental issues.

We got inspiration for writing this paper after demonstrating a solar-based watering system for plants for multi-story buildings in Adi Shankara Asianet News Young Scientists Award-2018. We are thankful for the support from respected Mr. N. Singh, Principal, DPS Roorkee and parents for support and suggestions in writing this paper.

\section{Conclusion}

In this paper, a simple approach is presented to provide water to the plants which are in the balcony when no one is inside the house for a few days. The advantage of the proposed approach is that there is no need for any advanced communication technology such as wifi, mobile technology, etc. Here, only four plants have been selected. In the future, the proposed simple approach will be extended to a large number of plants. Further, the proposed idea can be extended for agricultural use also.

\section{References}

[1] https://www.workingmother.com/blogs/mommyfavorites/five-reasons-why-we-should-take-careearth

[2] https://www.governancenow.com/views/interview /how-one-building-gets-pure-air-right-in-themiddle-of-delhi

[3] https://rgsenergy.com/how-solar-panels-work/thebasics-of-solar-power

[4] https://en.wikipedia.org/wiki/Solar_energy

[5] J. Uddin et. al, Automated Irrigation system using solar power, 7 th International Conference on 
Electrical and Computer Engineering, Dhaka, Bangladesh (2012).

[6] T. A. Binshad, K. Vijayakumar, M. Kaleeswari, PV based water pumping system for agricultural irrigation, Front. Energy, 10, 3, 319-328, (2016).

[7] R. K. Megalingam and V. V. Gedela, Solar powered automated water pumping system for eco-friendly irrigation, Proceedings of the International conférence on Inventive Computing and Informatics (ICICI), Coimbatore, India (2017).

[8] A. Agrawal et. al., Microcontroller based Irrigation system solar powered using solar powered using moisture sensing technology, 8th International Conference on Cloud Computing, Data Science \& Engineering, Noida, India (2018). 